mode of action of the clostridial toxin is not yet clear but it may elicit a local Schwartzman reaction, usually resulting in mucosal changes identical with those of acute ischaemia. ${ }^{45}$ In our patient the location of the vascular damage differed from that postulated in classical drug-associated pseudomembranous enterocolitis because the small vessels of the entire bowel wall were affected. Whether this was due to the specific pharmacokinetics of clindamycin or modification of the vascular reaction to putative bacterial toxin by steroids or immunological dysfunction associated with sarcoid, or both, remains speculative.

We thank Dr B Keogh, Meath Hospital, Dublin, for clinical data.

${ }^{1}$ Price, A B, and Davies, D R, fournal of Clinical Pathology, 1977, 30, 1.

2 Bartlett, J G, et al, fournal of Infectious Diseases, 1977, 136, 701.

${ }^{3}$ Keighley, M R B, et al, British Medical fournal, 1978, 2, 1667.

4 Bogomoletz, W V, Gut, 1976, 17, 483.

${ }^{5}$ Morson, B C, in Systemic Pathology, ed W St C Symmers, 2nd edn, vol 3, p 1109. London, Churchill Livingstone, 1978.

(Accepted 23 August 1979)

School of Pathology, Trinity College, Dublin 2, Eire

E C SWEENEY, FRCPI, MRCPATH, senior lecturer in histopathology J P SHEEHAN, MB, senior house officer in histopathology

\section{Reversal of narcotic-induced delay in gastric emptying and paracetamol absorption by naloxone}

Narcotic analgesics inhibit gastric emptying and consequently delay the absorption of orally administered drugs such as paracetamol. ${ }^{1-3}$ This increases the risk of aspiration of gastric contents during induction of anaesthesia in women in labour after narcotic analgesics and is not reversed by metoclopramide. ${ }^{1}$ We have investigated the effect of the specific narcotic antagonist naloxone on narcotic-induced delay in gastric emptying.

\section{Subjects, methods, and results}

Gastric emptying and paracetamol absorption $(20 \mathrm{mg} / \mathrm{kg})$ were measured simultaneously in four fasting healthy volunteers aged 26-39 years, as described. ${ }^{2}$ Each subject was studied "blind" on three occasions in random order at least seven days apart, once after placebo injections, once 30 minutes after pentazocine $60 \mathrm{mg}$ intramuscularly, and once 30 minutes after pentazocine and immediately after naloxone $1.2 \mathrm{mg}$ intravenously.

Gastric emptying and paracetamol absorption were rapid in all the control studies (see table). The mean time to empty half of the ingested dose was 13 minutes and the mean peak plasma paracetamol concentration $23.8 \mathrm{mg} / 1$ 22.5 minutes after ingestion. After pentazocine, however, gastric emptying and paracetamol absorption were greatly delayed in all subjects. Fifty per cent gastric emptying occurred at 97.3 minutes $(P<0.02$; paired $t$ test). The mean peak plasma paracetamol concentration was only $10.8 \mathrm{mg} / \mathrm{l}$, which occurred 160 minutes after ingestion $(P<0.05$ and $P<0.01$ respectively). This inhibition was largely reversed by naloxone. The gastricemptying measurements and mean time to peak plasma paracetamol concentration after pentazocine and naloxone did not differ significantly from control values $(27.8$ minutes and 25 minutes respectively). Nevertheless, the mean peak paracetamol concentration was only $15.0 \mathrm{mg} / \mathrm{l}$, which was significantly lower than control values $(P<0 \cdot 05)$. This may reflect the short duration of action of naloxone compared with pentazocine. The total amount of paracetamol absorbed was not influenced by pentazocine administered alone or with naloxone. In the control studies $75 \%, 79 \%$, and $74 \%$ of the

Effect of pentazocine and pentazocine/naloxone on gastric emptying and paracetamol absorption

\begin{tabular}{|c|c|c|c|c|}
\hline & & $\begin{array}{l}\text { Mean ( }+S E) \\
\text { time to } 50^{\prime \prime} \\
\text { gastric emptying } \\
\text { (minutes) }\end{array}$ & $\begin{array}{c}\text { Mean }(+\mathrm{SE}) \\
\text { peak plasma } \\
\text { paracetamol } \\
\text { concentration } \\
(\mu \mathrm{g} / \mathrm{ml})\end{array}$ & $\begin{array}{c}\text { Mean }( \pm S E) \\
\text { time to peak } \\
\text { concentration } \\
\text { (minutes) }\end{array}$ \\
\hline $\begin{array}{l}\text { Control .. } \quad \ldots \\
\text { Pentazocine } \quad \ldots \\
\text { Pentazocine/naloxone }\end{array}$ & $\begin{array}{l}\cdots \\
\cdots\end{array}$ & $\begin{array}{l}13 \cdot 0 \pm 3 \cdot 5 \\
97 \cdot 3 \pm 17 \cdot 6 \\
27 \cdot 8 \pm 7 \cdot 6\end{array}$ & $\begin{array}{l}23 \cdot 8 \pm 1 \cdot 9 \\
10 \cdot 8 \pm 0 \cdot 6 \\
15 \cdot 0 \pm 1 \cdot 8\end{array}$ & $\begin{array}{c}22 \cdot 5 \pm 1 \cdot 3 \\
160 \cdot 0 \pm 16 \cdot 3 \\
25 \cdot 0 \pm 1 \cdot 8\end{array}$ \\
\hline
\end{tabular}

administered doses of pentazocine and pentazocine and naloxone were recorded in the urine over 24 hours.

\section{Comment}

Gastric emptying and paracetamol absorption are severely inhibited by narcotic analgesics, and the delay in gastric emptying observed in women during labour is almost certainly attributable to narcotic analgesics. Metoclopramide does not reverse this delay. ${ }^{1}$ In this study naloxone largely reversed the effect of pentazocine on gastric emptying, though its effect was probably shorter. Larger doses of naloxone may produce a greater reversal of pentazocine's effects, and naloxone may more effectively reverse the effects of a pure narcotic agonist such as pethidine. When reversal of the effects of narcotic analgesics on gastric emptying is desirable-for example, immediately before anaesthesia during labour or in recurrent vomiting-intravenous naloxone reverses the delay in gastric emptying as well as the other effects of narcotics.

1 Nimmo, W S, Wilson, J, and Prescott, L F, Lancet, 1975, 1, 890.

${ }^{2}$ Nimmo, W S, et al, British fournal of Clinical Pharmacology, 1975, 2, 509.

${ }^{3}$ Gamble, J A S, et al, British fournal of Anaesthesia, 1976, 48, 1181.

(Accepted 23 August 1979)

\section{Royal Infirmary, Edinburgh EH3 9YW}

W S NIMMO, MRCP, lecturer in anaesthesia (present appointment: senior lecturer in anaesthesia, Western Infirmary, Glasgow)

R C HEADING, FRCP, senior lecturer in therapeutics and clinical pharmacology

J WILSON, FFARCS, consultant anaesthetist

L F PRESCOTT, MD, FRCP, reader in clinical pharmacology

\section{Isolation of Legionella pneumophila from blood culture}

The severe lobar type of pneumonia and the other manifestations of legionnaires' disease ${ }^{12}$ all support occurrence of an early bacteraemic phase in the illness. Though the causative organism has been cultured from lung tissue, pleural exudate, bronchial aspirate, and sputum on bacteriological media, ${ }^{34}$ it has proved difficult to demonstrate in blood. ${ }^{5}$ In the case now reported Legionella pneumophila, serogroup 1 , was recovered in broth culture from blood before death and also from postmortem lung tissue by inoculation on bacteriological medium and into yolk sacs of fertile hens' eggs.

\section{Case report}

A retired 61-year-old man who had worked as a factory cleaner was admitted to hospital in a semi-conscious state. He was a heavy smoker with a history of chronic cough and extreme breathlessness on exertion. A partial gastrectomy two years previously because of haematemesis from a peptic ulcer had been followed then by an episode of left ventricular failure, from which he had recovered. More recently he had been reasonably well until a week before admission, when his cough exacerbated with production of brownish sputum. His condition deteriorated slowly and after five days amoxycillin was started. Despite this treatment, increasing dyspnoea and drowsiness led to emergency admission. Urgent chest radiography showed extensive opacity on the left side. His haemoglobin concentration was 15.5 $\mathrm{g} / \mathrm{dl}$ and white cell count $6 \times 10^{9} / 1\left(6000 / \mathrm{mm}^{3}\right)$ with $85 \%$ neutrophils. Blood was taken for culture and treatment for his chest infection and heart condition started. He suffered respiratory and cardiac arrest, however, and died five hours later.

Blood was cultured in enrichment-broth medium of the following composition: Difco (yeast extract $5 \mathrm{~g}$, proteose peptone $15 \mathrm{~g}$ ); panmede liver extract $2.5 \mathrm{~g}$; L-cysteine $\mathrm{HCl} \mathrm{H}_{2} \mathrm{O} 0.4 \mathrm{~g}$; ferric pyrophosphate soluble $0.125 \mathrm{~g}$; sodium chloride $5 \mathrm{~g}$; deionised water 11 . After dissolving the ingredients the $\mathrm{pH}$ was adjusted to 6.9 and the medium sterilised by autoclaving at $121^{\circ} \mathrm{C}$ for 15 minutes. Legionella pneumophila were observed in the culture after five days' incubation, identified first with Gram's stain, dilute carbol fuchsin being the counter-stain, and confirmed as serogroup 1 by direct fluorescent antibody test followed by subculture on solid medium. ${ }^{4}$ Lung tissue in a $10 \%$ suspension was inoculated directly on enriched blood agar medium ${ }^{4}$ and incubated at $36^{\circ} \mathrm{C}$ in a humid atmosphere containing $5 \% \mathrm{CO}_{2}$. Typical colonies of $L$ pneumophila were detectable after three days' incubation and were identified as serogroup 1 in similar fashion to the blood culture. 


\section{Comment}

Since it first came into prominence legionnaires' disease has been mainly diagnosed retrospectively from the development of specific circulating antibody. Though the combination of pneumonia with other manifestations may permit a tentative diagnosis, sufficient to initiate treatment, laboratory confirmation early in the illness has been an urgent need. This recovery of the organism from blood and an increasing ability to recover it from bronchial aspirates or sputum indicates steady progress towards this objective.

We thank Dr W J Jeffcoate, consultant physician, City Hospital, Nottingham, for permission to report this case.

${ }^{1}$ Kirby, B D, et al, Annals of Internal Medicine, 1978, 89, 297.

2 Jenkins, P, et al, British fournal of Diseases of the Chest, 1979, 73, 31.

${ }^{3}$ Feeley, J C, et al, fournal of Clinical Microbiology, 1978, 8, 320.

${ }^{4}$ Greaves, P G, Sharp, F, and Macrae, A D, Lancet, 1979, 1, 551.

${ }^{5}$ Edelstein, P H, Meyer, R D, and Finegold, S M, Lancet, 1979, 1, 750.

(Accepted 12 October 1979)

Public Health Laboratory, University Hospital, Queen's Medical Centre, Nottingham NG7 2UH

A D MACRAE, MD, consultant microbiologist

P W GREAVES, BA, senior chief medical laboratory scientific officer

City Hospital, Hucknall Road, Nottingham NG5 1PB

P PLATTS, BM, senior house officer

\section{Successful management of cardiac tamponade in two cases of leukaemia}

Cardiac tamponade is an uncommon complication of leukaemia. We report the cases of a child with acute lymphoblastic leukaemia (ALL) and an adult with chronic myelomonocytic leukaemia (CMML) who developed this complication.

\section{Case reports}

(1) A 12-year-old boy was admitted to hospital with sudden onset of leftsided chest pain. He looked ill, anaemic, and preferred sitting in bed to lying. He had moderate hepatosplenomegaly and generalised lymphadenopathy, distant heart sounds, and the cardiac apex displaced to the left anterior axillary line. His haemoglobin was $6.9 \mathrm{~g} / \mathrm{dl}$, white cell count $130 \times 10^{9} / 1$ $\left(130000 / \mathrm{mm}^{3}\right)$, and platelets $120 \times 10^{9} / 1\left(120000 / \mathrm{mm}^{3}\right)$. The blood film and bone marrow were diagnostic of ALL. Radiographs of chest and electrocardiograms suggested a pericardial effusion. Chemotherapy for ALL was started. Over the next four days he deteriorated with shortness of breath, a much raised jugular venous pressure (JVP), and pulsus paradoxus. Ultrasound studies confirmed incipient cardiac tamponade. Under cover of two units of fresh frozen plasma and four units of platelet-rich plasma, because the prothrombin time was prolonged and the platelet count had dropped to $13 \times 10^{9} / 1\left(13000 / \mathrm{mm}^{3}\right), 500 \mathrm{ml}$ of dark, blood-stained fluid was aspirated from the pericardium. After that he felt immediate relief of symptoms and a radiograph showed a smaller cardiac shadow. He was discharged 13 days after admission and survived a further 30 months.

(2) A 66-year-old man diagnosed five months previously as a case of CMML was admitted to hospital with a two-week history of shortness of breath, attacks of nocturnal dyspnoea, and fatigue. His pulse rate was $100 / \mathrm{min}$ with paradox, the JVP was raised to the angle of jaw, and he had hepatomegaly. His apex beat was not palpable and heart sounds were distant. A chest radiograph and ultrasound showed a large pericardial effusion with incipient tamponade. His haemoglobin was $10.5 \mathrm{~g} / \mathrm{dl}$, white cells $19 \cdot 1 \times 10^{9} / 1(19100 /$ $\left.\mathrm{mm}^{3}\right)$, and platelets $70 \times 10^{9} / 1\left(70000 / \mathrm{mm}^{3}\right)$. Under cover of 12 units of platelet concentrates and four units of fresh frozen plasma the pericardium was opened and $900 \mathrm{ml}$ of blood removed. Bleeding points were arrested and tissue for biopsy taken from an area suspicious of infiltrate. Symptomatic relief was dramatic and the JVP normal after six hours. He was transfused with four units of packed red cells and two units of fresh frozen plasma immediately after the operation. Six units platelet concentrates were given daily for three days and two tablets co-trimoxazole 12 hourly for two weeks. Recovery was uneventful and he was well and in full-time employment five months after discharge.

\section{Comment}

Although there are single reports of cardiac tamponade in acute leukaemia $a^{1-4}$ we know of none of cardiac tamponade in CMML. Interestingly, only in Rab and Yee's case ${ }^{4}$ was the effusion distinctly haemorrhagic. Two different approaches were used in the management of our cases. An open operative evacuation of pericardial effusion has advantages in that clots may be removed, blood vessels supplying the bleeding area tied off, and tissue for biopsy taken from any infiltrated area. A recurrence of the haemopericardium is unlikely after open drainage owing to adhesions forming within the pericardial cavity. But in an acute leukaemia such a procedure might be too hazardous and a conservative standard needle aspiration seems to be more suitable. Many leukaemic patients may now have a prolonged survival. Such acute emergencies as cardiac tamponade should not in any way lessen the enthusiasm of the therapist.

We thank Drs C G Geary and D R Smith and Mr D R Walker for help in diagnosis and management in case 2.

${ }^{1}$ Battle, Constance N, Don Figlio, T A, and Miller, A R, fournal of Pediatrics, 1969, 75, 692

${ }^{2}$ Ghia, B L, DaCosta, J L, and Ransome, G A, Thorax, 1973, 28, 657.

3 Wendkos, M H, American Heart fournal, 1941, 22, 417.

4 Rab, S M, and Yee, A, British Medical fournal, 1967, 1, 612.

(Accepted 24 August 1979)

\section{Leeds Regional Cardio-Thoracic Centre, Killingbeck Hospital,} Leeds LS14 6UQ

S SOBOLEWSKI, MRCPATH, senior registrar

N SREEHARAN, MD, MRCP, research senior registrar

S M RAJAH, MB, MRCP, consultant haematologist

\section{Vancouver style}

All manuscripts submitted to the $B M F$ from now on should conform to the uniform requirements for manuscripts submitted to biomedical journals (known as the Vancouver style).

The $B M F$, together with many other international biomedical journals, has agreed to accept articles prepared in accordance with the Vancouver style and will be introducing the system from January 1980. The style (described in full in BMF, 24 February, p 532) is intended to standardise requirements for authors and covers text format, presentation of methods and results, use of SI units, and the form of tables and illustrations. All the participating journals have also agreed to introduce a standard form of references.

In future references to papers submitted to the $B M F$ should include: the names of all authors if there are fewer than seven or, if there are more, the first three followed by et al; the title of journal articles or book chapters; the titles of journals abbreviated according to the style of Index Medicus; and the first and final page numbers of the article or chapter.

Examples of common forms of references are:

${ }^{1}$ International Steering Committee of Medical Editors. Uniform requirements for manuscripts submitted to biomedical journals. Br Med F 1979;1:532-5.

2 Soter NA, Wasserman SI, Austen KF. Cold urticaria: release into the circulation of histamine and eosinophil chemotactic factor of anaphylaxis during cold challenge. $N$ Engl f Med 1976;294:687-90.

${ }^{3}$ Weinstein L, Swartz MN. Pathogenic properties of invading microorganisms. In: Sodeman WA Jr, Sodeman WA, eds. Pathologic physiology: mechanisms of disease. Philadelphia: W B Saunders, 1974:457-72.

Up to the beginning of October some 100 journals had agreed to accept articles in the Vancouver style, and a full list will be printed early in 1980 . 